\title{
Epidemiology and economic burden of osteoporosis in Switzerland
}

\author{
A. Svedbom • M. Ivergård • E. Hernlund • R. Rizzoli • \\ J. A. Kanis
}

Received: 27 March 2014 / Accepted: 17 June 2014 / Published online: 27 June 2014

(C) International Osteoporosis Foundation and National Osteoporosis Foundation 2014

\begin{abstract}
Summary This report describes the epidemiology, economic burden and treatment of osteoporosis in Switzerland.

Introduction Osteoporosis is characterized by reduced bone mass and disruption of bone architecture, resulting in increased risks of fragility fractures which represent the main clinical consequence of the disease. Fragility fractures are associated with substantial pain and suffering, disability and even death for the affected patients and substantial costs to society. The aim of this report is to describe the epidemiology and economic burden of fragility fractures as a consequence of osteoporosis in Switzerland, as a detailed addition to the report for the European Union (EU27): "Osteoporosis in the European Union: Medical Management, Epidemiology and Economic Burden".

Methods The literature on fracture incidence and costs of fractures in Switzerland was reviewed and incorporated into a model estimating the clinical and economic burden of osteoporotic fractures in 2010. Furthermore, data on sales of osteoporosis treatments and the population at high risk of
\end{abstract}

A. Svedbom $\cdot$ M. Ivergård $\cdot$ E. Hernlund

OptumInsight, Stockholm, Sweden

E. Hernlund

Unit of Dermatology and Venerology, Department of Medicine,

Karlolinska Institutet, Stockholm, Sweden

R. Rizzoli $(\bowtie)$

Geneva University Hospitals and Faculty of Medicine, 1211 Geneva

14, Switzerland

e-mail: Rene.Rizzoli@unige.ch

J. A. Kanis

Centre for Metabolic Bone Diseases, University of Sheffield,

Sheffield, UK fracture were used to estimate treatment uptake and treatment gap.

Results It was estimated that approximately 74,000 new fragility fractures were sustained in Switzerland in 2010, comprising 14,000 hip fractures, 11,000 vertebral fractures, 13,000 forearm fractures and 36,000 other fractures (i.e. fractures of the pelvis, rib, humerus, tibia, fibula, clavicle, scapula, sternum and other femoral fractures). The economic burden of incident and previous fragility fractures was estimated at $\mathrm{CHF}$ 2,050 million for the same year. Incident fractures represented $76 \%$ of this cost, long-term fracture care $21 \%$ and pharmacological prevention $3 \%$. Previous and incident fractures also accounted for 24,000 quality-adjusted life years (QALYs) lost during 2010. When accounting for the demographic projections for 2025, the number of incident fractures was estimated at 98,786 in 2025 , representing an increase of 25,000 fractures. Hip, clinical vertebral (spine), forearm and other fractures were estimated to increase by 4,900, 3,200, 3,500 and 13,000 , respectively. The burden of fractures in terms of costs (excluding value of QALYs lost) in Switzerland in 2025 was estimated to increase by $29 \%$ to CHF 2,642 million. Though the uptake of osteoporosis treatments increased from 2001, the proportion of patients aged 50 or above who received treatment remained at low levels in the past few years. The majority of women at high fracture risk do not receive active treatment.

Conclusions In spite of the high cost of osteoporosis, a substantial treatment gap and projected increase of the economic burden driven by an aging population, the use of pharmacological prevention of osteoporosis is significantly less than optimal, suggesting that a change in health care policy concerning the disease is warranted.

Keywords Osteoporosis $\cdot$ Epidemiology $\cdot$ Economic burden 
Table 1 Population at risk: men and women over the age of 50 years in Switzerland, 2010 [8]

\begin{tabular}{lrrr}
\hline Age (years) & Women & Men & \multicolumn{1}{l}{ All } \\
\hline $50-59$ & 556,000 & 545,000 & $1,101,000$ \\
$60-69$ & 477,000 & 435,000 & 912,000 \\
$70-79$ & 351,000 & 275,000 & 626,000 \\
$80-89$ & 238,000 & 116,000 & 354,000 \\
$80+$ & 276,000 & 126,000 & 402,000 \\
$50+$ & $1,660,000$ & $1,381,000$ & $3,041,000$ \\
\hline
\end{tabular}

\section{Introduction}

Osteoporosis is characterized by reduced bone mass and disruption of bone architecture, resulting in increased risks of fragility fractures which represent the main clinical consequence of the disease. Fragility fractures are associated with substantial pain and suffering, disability and even death for the affected patients and substantial costs to society. The aim of this report was to characterize the economic burden of osteoporosis in Switzerland in 2010 and beyond.

\section{Methods}

The literature on fracture incidence and costs of fractures in Switzerland was reviewed and incorporated into a model estimating the clinical and economic burden of osteoporotic fractures in 2010. Details of the methods used are found in Chapters 3 and 4 of the report "Osteoporosis in the European Union: Medical Management, Epidemiology and Economic Burden" [1], published in 2013 in Archives of Osteoporosis.

\section{Epidemiology of osteoporosis in Switzerland}

For the purpose of this report, the population at risk of osteoporosis was considered to include men and women $\geq 50$ years. The number of men and women $\geq 50$ years of age amounted to

Table 2 Estimated number of women and men with osteoporosis (defined as a T-score $\leq$ $-2.5 \mathrm{SD}$ ) in Switzerland by age using female-derived reference ranges at the femoral neck, 2010 [9]

\begin{tabular}{lrr}
\hline Age group (years) & Women & \multicolumn{1}{c}{ Men } \\
\hline $50-54$ & 19,026 & 7,525 \\
$55-59$ & 24,384 & 8,540 \\
$60-64$ & 34,320 & 12,992 \\
$65-69$ & 47,874 & 15,614 \\
$70-74$ & 54,684 & 12,636 \\
$75-79$ & 58,125 & 11,639 \\
$80+$ & 130,272 & 20,916 \\
$50+$ & 368,685 & 89,862 \\
\hline
\end{tabular}

Table 3 Incidence per 100,000 person years of hip, clinical vertebral, forearm and other fractures in Switzerland by age

\begin{tabular}{|c|c|c|c|c|}
\hline \multirow[t]{2}{*}{ Age (years) } & \multicolumn{4}{|c|}{ Fracture at the } \\
\hline & Hip & Vertebra & Forearm & Other \\
\hline \multicolumn{5}{|l|}{ Women } \\
\hline $50-54$ & 17 & 113 & 319 & 110 \\
\hline $55-59$ & 54 & 76 & 232 & 471 \\
\hline $60-64$ & 67 & 328 & 743 & 259 \\
\hline $65-69$ & 139 & 157 & 485 & 475 \\
\hline $70-74$ & 247 & 260 & 718 & 700 \\
\hline $75-79$ & 473 & 721 & 759 & 996 \\
\hline $80-84$ & 1,169 & 1,635 & 1,449 & 1,987 \\
\hline $85+$ & 2,937 & 1,390 & 1,135 & 4,933 \\
\hline \multicolumn{5}{|l|}{ Men } \\
\hline $50-54$ & 35 & 89 & 132 & 155 \\
\hline $55-59$ & 76 & 156 & 158 & 710 \\
\hline $60-64$ & 65 & 262 & 130 & 643 \\
\hline $65-69$ & 135 & 187 & 173 & 873 \\
\hline $70-74$ & 139 & 299 & 69 & 714 \\
\hline $75-79$ & 326 & 223 & 191 & 869 \\
\hline $80-84$ & 363 & 799 & 95 & 964 \\
\hline $85+$ & 1,394 & 482 & 484 & 4,036 \\
\hline
\end{tabular}

$1,381,000$ and 1,660,000, respectively, in Switzerland in 2010 (Table 1).

In the population at risk, the number of individuals with osteoporosis - as defined by the WHO diagnostic criteria applied to the femoral neck-was estimated at 460,000 (Table 2). There were 20.8 DXA units/million inhabitants, and guidelines for the assessment and treatment of osteoporosis are available [2]. A country-specific FRAX model

Table 4 Estimated number of incident fractures in Switzerland, 2010

\begin{tabular}{lrrrrr}
\hline \multirow{2}{*}{ Age (years) } & \multicolumn{2}{l}{ Fracture at the } & \multirow{2}{*}{ All fractures } \\
\cline { 2 - 4 } & Hip & Vertebra & Forearm & Other & \\
\hline Women & & & & & \\
$50-74$ & 1,735 & 2,697 & 6,305 & 6,460 & 17,197 \\
$75+$ & 8,886 & 4,871 & 4,528 & 16,092 & 34,376 \\
Total & 10,621 & 7,568 & 10,833 & 22,552 & 51,573 \\
Men & & & & & \\
$50-74$ & 1,233 & 2,306 & 1,588 & 8,205 & 13,333 \\
$75+$ & 1,980 & 1,089 & 693 & 5,523 & 9,286 \\
Total & 3,213 & 3,395 & 2,282 & 13,729 & 22,619 \\
Men and women & & & & & \\
$50-74$ & 2,968 & 5,002 & 7,893 & 14,665 & 30,529 \\
$75+$ & 10,866 & 5,960 & 5,221 & 21,615 & 43,663 \\
Total & 13,834 & 10,963 & 13,115 & 36,280 & 74,192 \\
\hline
\end{tabular}


Table 5 Proportion of men and women (in \%) with a prior hip or clinical vertebral fracture in Switzerland, 2010

\begin{tabular}{lll}
\hline Age (years) & Hip fracture & Vertebral fracture \\
\hline Women & & \\
$50-54$ & 0.0 & 0.2 \\
$55-59$ & 0.2 & 0.6 \\
$60-64$ & 0.5 & 1.5 \\
$65-69$ & 1.0 & 2.3 \\
$70-74$ & 1.9 & 3.1 \\
$75-79$ & 3.5 & 5.0 \\
$80-84$ & 6.6 & 8.7 \\
$85+$ & 15.8 & 14.0 \\
Men & & \\
$50-54$ & 0.1 & 0.2 \\
$55-59$ & 0.3 & 0.8 \\
$60-64$ & 0.6 & 1.5 \\
$65-69$ & 1.0 & 2.2 \\
$70-74$ & 1.6 & 2.7 \\
$75-79$ & 2.5 & 3.2 \\
$80-84$ & 3.9 & 4.4 \\
$85+$ & 8.5 & 6.0 \\
\hline
\end{tabular}

is also available for the assessment of fracture risk (http:// www.shef.ac.uk/FRAX/).

Data on the incidence of hip, vertebral and forearm fractures are available for Switzerland [3]. The incidence for "other" fractures was derived as described in the EU27 report [1] (Table 3).

The number of incident fractures in 2010 was estimated at 74,000 (Table 4). Incident hip, clinical spine, forearm and other fractures were estimated at 14,000, 11,000, 13,000 and 36,000 , respectively. Seventy percent of fractures occurred in women.

Table 6 Number of men and women in Switzerland with a prior hip or clinical vertebral fracture after the age of 50 years, 2010

\begin{tabular}{lcc}
\hline Age (years) & Hip fracture & Vertebral fracture \\
\hline Women & & \\
$50-74$ & 8,187 & 17,256 \\
$75+$ & 36,424 & 39,174 \\
Total & 44,611 & 56,430 \\
Men & & \\
$50-74$ & 7,134 & 14,881 \\
$75+$ & 9,936 & 9,943 \\
Total & 17,070 & 24,823 \\
Men and women & & \\
$50-74$ & 15,320 & 32,137 \\
$75+$ & 46,360 & 49,116 \\
Total & 61,680 & 81,253 \\
\hline
\end{tabular}

Table 7 Incidence (per 100,000) of causally related deaths in Switzerland within the first year after fracture (adjusted for comorbidities), 2010

\begin{tabular}{|c|c|c|c|}
\hline Age (years) & Hip & Clinical vertebral & Other fracture \\
\hline \multicolumn{4}{|l|}{ Women } \\
\hline $50-54$ & 397 & 516 & 10 \\
\hline $55-59$ & 641 & 788 & 19 \\
\hline $60-64$ & 842 & 978 & 27 \\
\hline $65-69$ & 1,056 & 1,157 & 40 \\
\hline $70-74$ & 1,416 & 1,461 & 64 \\
\hline $75-79$ & 1,740 & 1,681 & 109 \\
\hline $80-84$ & 1,985 & 1,757 & 221 \\
\hline $85-89$ & 2,637 & 2,050 & 462 \\
\hline $90+$ & 3,011 & 1,698 & 1,047 \\
\hline \multicolumn{4}{|l|}{ Men } \\
\hline $50-54$ & 1,163 & 1,396 & 18 \\
\hline $55-59$ & 1,523 & 1,731 & 31 \\
\hline $60-64$ & 1,808 & 1,945 & 49 \\
\hline $65-69$ & 2,115 & 2,146 & 76 \\
\hline $70-74$ & 2,569 & 2,446 & 116 \\
\hline $75-79$ & 3,275 & 2,904 & 194 \\
\hline $80-84$ & 4,320 & 3,508 & 363 \\
\hline $85-89$ & 6,261 & 4,576 & 676 \\
\hline $90+$ & 10,422 & 6,782 & 1,304 \\
\hline
\end{tabular}

A prior fracture was defined as a fracture in an individual who was alive during the index year (i.e. 2010) and which had occurred after the age of 50 years and before 2010. In the population $\geq 50$ years of age, the proportion of individuals who had suffered a fracture prior to 2010 was estimated at $2.0 \%$ for hip and $2.7 \%$ for clinical vertebral fractures. The estimated proportions of men and women with prior hip and vertebral fractures by age are presented in Table 5.

Table 8 The number of deaths in men and women in Switzerland in the first year after fracture attributable to the fracture event (causally related), 2010

\begin{tabular}{lrrr}
\hline \multirow{2}{*}{ Age (years) } & \multicolumn{2}{l}{ Fracture at the } \\
\cline { 2 - 4 } & Hip & Vertebra & Other \\
\hline Women & & & \\
$50-74$ & 21 & 32 & 3 \\
$75+$ & 210 & 85 & 113 \\
Total & 231 & 117 & 116 \\
Men & & & \\
$50-74$ & 27 & 49 & 6 \\
$75+$ & 124 & 43 & 43 \\
Total & 151 & 91 & 49 \\
Men and women & & \\
$50-74$ & 49 & 81 & 9 \\
$75+$ & 334 & 127 & 156 \\
Total & 383 & 208 & 165 \\
\hline
\end{tabular}


Table 9 One-year costs for relevant pharmaceuticals in Switzerland, 2010 [10]

\begin{tabular}{lc}
\hline & Annual drug cost (CHF) \\
\hline Alendronate & 469 \\
Risedronate & 667 \\
Ibandronate & 489 \\
Zoledronic acid & 421 \\
Raloxifene & 629 \\
Teriparatide & 6,376 \\
\hline
\end{tabular}

Table 10 Cost of osteoporosis (CHF) in Switzerland by age in men and women, 2010

\begin{tabular}{lrllr}
\hline $\begin{array}{l}\text { Age } \\
\text { (years) }\end{array}$ & $\begin{array}{l}\text { First year } \\
\text { fracture cost }\end{array}$ & $\begin{array}{l}\text { Long-term } \\
\text { disability } \\
\text { costs }\end{array}$ & $\begin{array}{l}\text { Fracture } \\
\text { prevention } \\
\text { cost }\end{array}$ & Total cost \\
\hline Women & & & & \\
50-74 & $296,616,249$ & $37,600,533$ & $32,270,586$ & $366,487,368$ \\
$75+$ & $808,643,124$ & $265,894,082$ & $20,381,780$ & $1,094,918,986$ \\
All & $1,105,259,373$ & $303,494,615$ & $52,652,366$ & $1,461,406,355$ \\
Men & & & & \\
$50-74$ & $253,595,483$ & $38,772,184$ & $5,137,307$ & $297,504,974$ \\
$75+$ & $206,776,516$ & $81,831,119$ & $2,264,754$ & $290,872,389$ \\
All & $460,371,999$ & $120,603,303$ & $7,402,061$ & $588,377,364$ \\
Women and men & & & 6 \\
$50-74$ & $550,211,732$ & $76,372,717$ & $37,407,893$ & $663,992,343$ \\
$75+$ & $1,015,419,641$ & $347,725,201$ & $22,646,534$ & $1,385,791,376$ \\
All & $1,565,631,372$ & $424,097,919$ & $60,054,427$ & $2,049,783,718$ \\
\hline
\end{tabular}

In the population over 50 years of age, the number of individuals with hip and vertebral fractures that occurred before 2010 was estimated at 62,000 and 81,000 , respectively (Table 6). Note that fractures sustained in 2010 were not included in the estimate.

The incidence of causally related deaths (per 100,000) in the first year after fracture by age is presented in Table 7. The number of causally related deaths in 2010 was estimated at 756 (Table 8). Hip, vertebral and other fractures accounted for 383, 208 and 165 deaths, respectively. Overall, approximately $61 \%$ of deaths occurred in women.

\section{Cost of osteoporosis in Switzerland including and excluding value of QALYs lost}

For the purpose of this report, the cost of osteoporosis in 2010 (excluding value of QALYs lost) was considered to consist of three components: (i) cost of fractures that occurred in 2010 ("first year costs"), (ii) cost of fractures sustained prior to year 2010 but which still incurred costs in 2010 ("long-term disability cost") and (iii) cost of pharmacological fracture prevention including administration and monitoring costs ("pharmacological fracture prevention costs"). See Chapter 4 of the EU27 report [1] for further details.

In Switzerland, the costs of hip, vertebral and wrist fractures have been estimated to range from CHF 34,374 to 38,871 , CHF 19,790 to 36,622 and CHF 7,000 to 25,454 depending on age, respectively [4]. One Swiss franc (CHF) corresponds to 0.82 euro. Costs for other fractures were estimated as described in Chapter 4 of the EU27 report [1].

Long-term disability costs were estimated by multiplying the yearly cost of residing in a nursing home (CHF
Table 11 Total cost (CHF) in 2010 by fracture site in men and women in Switzerland. Note that costs for fracture prevention, therapy and monitoring are not included

\begin{tabular}{lrrrrr}
\hline Age (years) & \multicolumn{1}{l}{ Hip } & \multicolumn{1}{l}{ Spine } & \multicolumn{1}{l}{ Forearm } & \multicolumn{1}{l}{ Other } & \multicolumn{1}{l}{ All } \\
\hline Women & & & & & \\
$50-74$ & $100,985,955$ & $54,536,166$ & $48,202,428$ & $130,492,233$ & $334,216,782$ \\
$75+$ & $572,595,695$ & $122,545,405$ & $71,858,711$ & $307,537,396$ & $1,074,537,207$ \\
All & $673,581,650$ & $177,081,571$ & $120,061,140$ & $438,029,629$ & $1,408,753,989$ \\
Men & & & & & \\
$50-74$ & $82,322,724$ & $45,552,418$ & $11,995,901$ & $152,496,625$ & $292,367,667$ \\
$75+$ & $144,371,747$ & $23,210,565$ & $12,025,998$ & $108,999,327$ & $288,607,635$ \\
All & $226,694,470$ & $68,762,983$ & $24,021,898$ & $261,495,951$ & $580,975,303$ \\
Women and men & & & & & \\
$50-74$ & $183,308,679$ & $100,088,584$ & $60,198,329$ & $282,988,858$ & $626,584,449$ \\
$75+$ & $716,967,441$ & $145,755,969$ & $83,884,709$ & $416,536,723$ & $1,363,144,842$ \\
All & $900,276,120$ & $245,844,553$ & $144,083,038$ & $699,525,580$ & $1,989,729,291$ \\
\hline
\end{tabular}




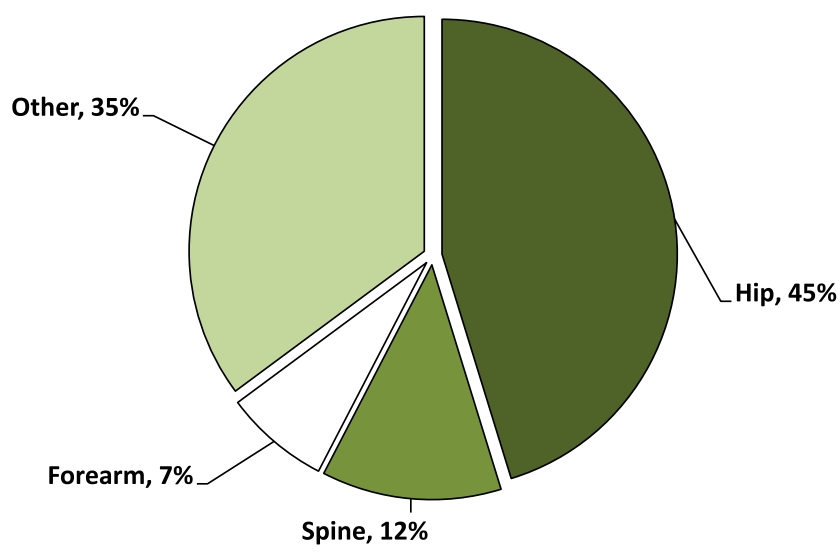

Fig. 1 Share (\%) of fracture cost by fracture site in Switzerland. Note that costs for fracture prevention therapy and monitoring are not included

74,294 [5]) with the simulated number of individuals with prior fractures that had been transferred to a nursing home due to the fracture.

Annual drug costs (CHF) for individual treatments are shown in Table 9. In addition, it was assumed that patients on treatment made an annual physician visit costing CHF 91

Table 12 Number of QALYs lost due to fractures during 2010 in men and women in Switzerland according to age

\begin{tabular}{|c|c|c|c|}
\hline & \multicolumn{3}{|c|}{ Age (years) } \\
\hline & $50-74$ & $75+$ & $50+$ \\
\hline \multicolumn{4}{|l|}{ Women } \\
\hline Incident hip fractures & 415 & 1,832 & 2,247 \\
\hline Incident vertebral fractures & 892 & 1,403 & 2,294 \\
\hline Incident forearm fractures & 222 & 138 & 36 \\
\hline Incident other fractures & 772 & 1,652 & 2,425 \\
\hline Prior hip fractures & 1,282 & 4,872 & 6,15 \\
\hline Prior vertebral fractures & 966 & 1,888 & 2,85 \\
\hline Total & 4,549 & 11,785 & 16,334 \\
\hline \multicolumn{4}{|l|}{ Men } \\
\hline Incident hip fractures & 299 & 471 & 770 \\
\hline Incident vertebral fractures & 762 & 347 & 1,110 \\
\hline Incident forearm fractures & 56 & 23 & \\
\hline Incident other fractures & 973 & 627 & 1,600 \\
\hline Prior hip fractures & 1,114 & 1,470 & 2,584 \\
\hline Prior vertebral fractures & 826 & 526 & 1,351 \\
\hline Total & 4,029 & 3,464 & 7,493 \\
\hline \multicolumn{4}{|l|}{ Men and women } \\
\hline Incident hip fractures & 714 & 2,303 & 3,017 \\
\hline Incident vertebral fractures & 1,654 & 1,750 & 3,404 \\
\hline Incident forearm fractures & 278 & 161 & 438 \\
\hline Incident other fractures & 1,745 & 2,279 & 4,025 \\
\hline Prior hip fractures & 2,395 & 6,343 & 8,73 \\
\hline Prior vertebral fractures & 1,792 & 2,413 & 4,205 \\
\hline Total & 8,578 & 15,249 & 23,82 \\
\hline
\end{tabular}

Table 13 Value of lost QALYs (CHF) in men and women in Switzerland in 2010

\begin{tabular}{lrrr}
\hline & $\begin{array}{l}1 \times \mathrm{GDP} / \\
\text { capita }\end{array}$ & $\begin{array}{l}2 \times \mathrm{GDP} / \\
\text { capita }\end{array}$ & $\begin{array}{l}\text { l } \\
\text { capita }\end{array}$ \\
\hline Incident hip fractures & $205,296,216$ & $410,592,432$ & $615,888,648$ \\
$\begin{array}{l}\text { Incident vertebral } \\
\text { fractures }\end{array}$ & $231,621,487$ & $463,242,975$ & $694,864,462$ \\
$\begin{array}{l}\text { Incident forearm } \\
\text { fractures }\end{array}$ & $29,830,907$ & $59,661,814$ & $89,492,721$ \\
$\begin{array}{l}\text { Incident other fractures } \\
\text { Prior hip fractures }\end{array}$ & $273,829,405$ & $547,658,810$ & $821,488,215$ \\
Prior vertebral fractures & $2894,528,606$ & $1,189,057,213$ & $1,783,585,819$ \\
Total & $1,621,207,660$ & $3,242,415,321$ & $4,863,622,981$ \\
\hline & & & \\
\hline
\end{tabular}

[5] and a DXA scan costing CHF 75 [5] every second year to monitor treatment. The cost of osteoporosis in 2010 was estimated at CHF 2,050 million (Table 10). First year costs, subsequent year costs and pharmacological fracture prevention costs amounted to CHF 1,566 million, CHF 424 million and CHF 60 million, respectively. It is notable that pharmacological fracture prevention costs amounted to only $2.9 \%$ of the total cost.

When stratifying costs of osteoporosis by fracture type, hip fractures were the most costly (CHF 900 million) followed by other fractures (CHF 700 million), spine fractures (CHF 246 million) and forearm fractures (CHF 144 million) (Table 11

Table 14 Population projections in Switzerland by age and sex [11]

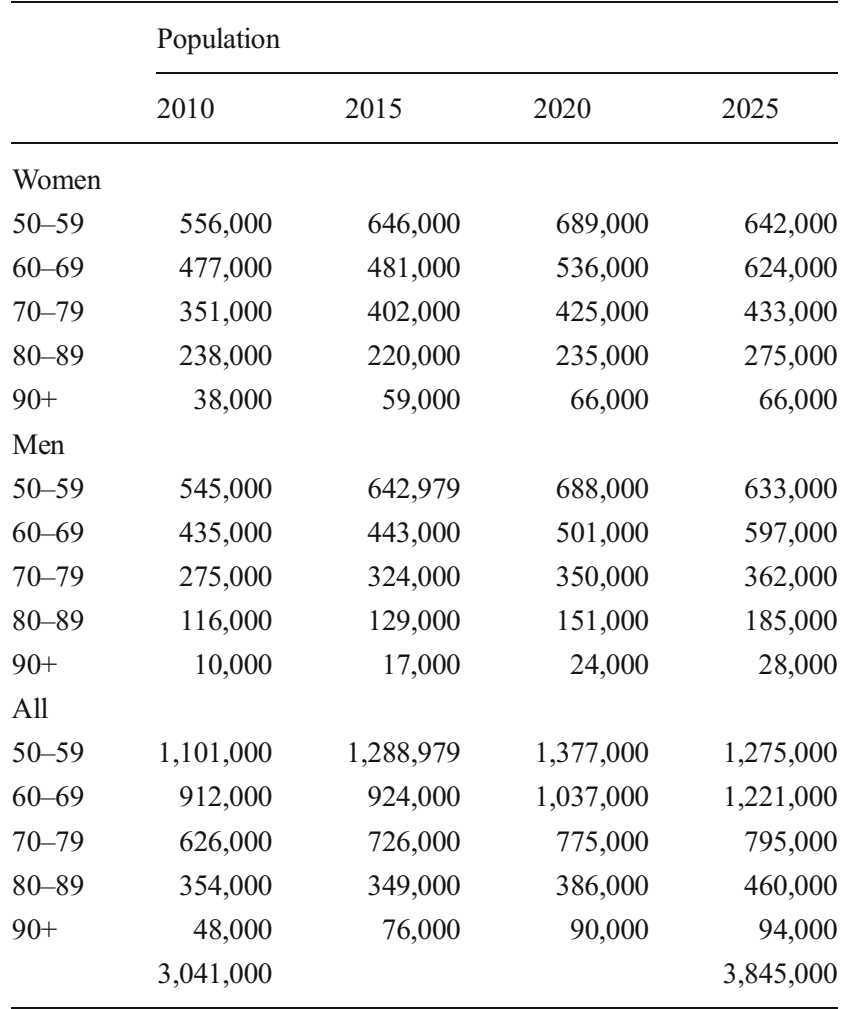


Table 15 Projected annual number of incident fractures in 2010 and 2025 by fracture site and age in men and women in Switzerland

\begin{tabular}{|c|c|c|c|c|c|c|c|c|}
\hline & \multicolumn{2}{|l|}{ Hip } & \multicolumn{2}{|l|}{ Spine } & \multicolumn{2}{|c|}{ Forearm } & \multicolumn{2}{|l|}{ Other } \\
\hline & 2010 & 2025 & 2010 & 2025 & 2010 & 2025 & 2010 & 2025 \\
\hline \multicolumn{9}{|c|}{ Women } \\
\hline $50-74$ & 1,735 & 2,127 & 2,697 & 3,344 & 6,305 & 7,814 & 6,460 & 7,938 \\
\hline $75+$ & 8,886 & 11,530 & 4,871 & 6,121 & 4,528 & 5,687 & 16,092 & 20,897 \\
\hline All & 10,621 & 13,657 & 7,568 & 9,466 & 10,833 & 13,501 & 22,552 & 28,834 \\
\hline \multicolumn{9}{|l|}{ Men } \\
\hline $50-74$ & 1,233 & 1,575 & 2,306 & 2,974 & 1,588 & 1,994 & 8,205 & 10,669 \\
\hline $75+$ & 1,980 & 3,463 & 1,089 & 1,712 & 693 & 1,153 & 5,523 & 9,786 \\
\hline All & 3,213 & 5,038 & 3,395 & 4,686 & 2,282 & 3,148 & 13,729 & 20,456 \\
\hline \multicolumn{9}{|c|}{ Women and men } \\
\hline $50-74$ & 2,968 & 3,702 & 5,002 & 6,318 & 7,893 & 9,808 & 14,665 & 18,607 \\
\hline $75+$ & 10,866 & 14,994 & 5,960 & 7,834 & 5,221 & 6,841 & 21,615 & 30,683 \\
\hline All & 13,834 & 18,695 & 10,963 & 14,151 & 13,115 & 16,649 & 36,280 & 49,290 \\
\hline
\end{tabular}

and Fig. 1). Please note that costs for pharmacological fracture prevention were not included given that they could not be allocated to specific fracture sites.

The number of quality-adjusted life years (QALYs) lost due to osteoporosis in 2010 was estimated at 23,827 (Table 12). Prior fractures accounted for $54 \%$ of the total loss and $69 \%$ of the loss occurred in women. The monetary value of a QALY was varied between one and three times the gross domestic product (GDP) per capita set at CHF 68,040. Assuming a QALY is valued at two times the GDP/capita, the total cost of the QALYs lost was estimated at CHF 3.24 billion (Table 13).

When the cost of osteoporosis was combined with the value of QALYs lost (valued at $2 \times$ GDP), the cost of osteoporosis amounted to CHF 5.3 billion in Switzerland in 2010. Incident fracture, prior fracture, pharmacological fracture

Table 16 Current and future cost of (CHF 000,000) osteoporosis (excluding value of QALYs lost) by age and calendar year in men and women in Switzerland

\begin{tabular}{|c|c|c|c|c|}
\hline & 2010 & 2015 & 2020 & 2025 \\
\hline \multicolumn{5}{|l|}{ Women } \\
\hline $50-74$ & 366 & 396 & 415 & 444 \\
\hline $75+$ & 1,095 & 1,167 & 1,250 & 1,353 \\
\hline All & 1,461 & 1,563 & 1,665 & 1,797 \\
\hline \multicolumn{5}{|l|}{ Men } \\
\hline $50-74$ & 298 & 324 & 348 & 377 \\
\hline $75+$ & 291 & 339 & 401 & 468 \\
\hline All & 588 & 663 & 749 & 845 \\
\hline \multicolumn{5}{|c|}{ Women and men } \\
\hline $50-74$ & 664 & 719 & 763 & 821 \\
\hline $75+$ & 1,386 & 1,506 & 1,651 & 1,821 \\
\hline All & 2,050 & 2,226 & 2,414 & 2,642 \\
\hline
\end{tabular}

prevention and value of QALYs lost accounted for 30, 8, 1 and $61 \%$, respectively.

\section{Economic burden of osteoporosis up to 2025}

The population above 50 years of age is expected to increase from 3.0 million in 2010 to 3.8 million in 2025 , corresponding to an increase of $26 \%$ (Table 14). The total number of fractures was estimated to rise from 74,000 in 2010 to 99,000 in 2025 (Table 15), corresponding to an increase of $33 \%$. Hip, clinical spine, forearm and other fractures increased by 4,900, 3,200, 3,500 and 13,010 , respectively. The increase in the number of fractures ranged from 27 to $36 \%$, depending on

Table 17 Projected QALYs lost due to incident and prior fractures for the year 2010 and 2025 by age in men and women in Switzerland

\begin{tabular}{|c|c|c|c|c|c|c|}
\hline & \multicolumn{2}{|c|}{ Incident fractures } & \multicolumn{2}{|c|}{ Prior fractures } & \multicolumn{2}{|c|}{ All fractures } \\
\hline & 2010 & 2025 & 2010 & 2025 & 2010 & 2025 \\
\hline \multicolumn{7}{|l|}{ Women } \\
\hline $50-74$ & 2,301 & 2,839 & 2,248 & 2,459 & 4,549 & 5,298 \\
\hline $75+$ & 5,025 & 6,430 & 6,760 & 7,544 & 11,785 & 13,974 \\
\hline All & 7,327 & 9,269 & 9,007 & 10,003 & 16,334 & 19,271 \\
\hline \multicolumn{7}{|l|}{ Men } \\
\hline $50-74$ & 2,090 & 2,696 & 1,939 & 2,254 & 4,029 & 4,950 \\
\hline $75+$ & 1,468 & 2,517 & 1,996 & 2,724 & 3,464 & 5,241 \\
\hline All & 3,558 & 5,213 & 3,935 & 4,978 & 7,493 & 10,191 \\
\hline \multicolumn{7}{|c|}{ Women and men } \\
\hline $50-74$ & 4,391 & 5,535 & 4,187 & 4,713 & 8,578 & 10,248 \\
\hline $75+$ & 6,494 & 8,947 & 8,756 & 10,268 & 15,249 & 19,215 \\
\hline All & 10,885 & 14,482 & 12,943 & 14,981 & 23,827 & 29,463 \\
\hline
\end{tabular}


Table 18 Present and future cost (CHF 000,000) of fracture (direct cost and cost of QALYs) by age and calendar year in men and women in Switzerland assuming the uptake of treatment remains unchanged

\begin{tabular}{lrrrr}
\hline & 2010 & 2015 & 2020 & 2025 \\
\hline Women & & & & \\
$50-74$ & 985 & 1,048 & 1,096 & 1,165 \\
$75+$ & 2,699 & 2,858 & 3,032 & 3,255 \\
All & 3,684 & 3,906 & 4,129 & 4,419 \\
Men & & & & \\
$50-74$ & 846 & 906 & 972 & 1,051 \\
$75+$ & 762 & 858 & 999 & 1,181 \\
All & 1,608 & 1,764 & 1,971 & 2,232 \\
Women and men & & & & \\
$50-74$ & 1,831 & 1,954 & 2,068 & 2,216 \\
$75+$ & 3,461 & 3,716 & 4,032 & 4,436 \\
All & 5,292 & 5,670 & 6,100 & 6,652 \\
\hline
\end{tabular}

the fracture site. The increase was estimated to be particularly marked in men (47\%) compared to women $(27 \%)$. It should be noted that the forecasts assume constant fracture incidence rates with time. However, small decreases in age-adjusted incidence for hip fracture incidence rates have been observed in recent years in Switzerland [6,7], potentially rendering the estimates biased upwards.

The cost of osteoporosis (excluding value of QALYs lost) was estimated to rise from CHF 2.1 billion in 2010 to CHF 2.6 billion in 2025, corresponding to an increase of $29 \%$ (Table 16). Costs incurred in women and men increased by 23 and $44 \%$, respectively.

The total number of QALYs lost due to fracture was estimated to rise from 24,000 in 2010 to 29,000 in 2025 , corresponding to an increase of $24 \%$ (Table 17). The increase was estimated to be particularly marked in men (36\%) compared to women $(18 \%)$. Incident and prior fractures accounted for 64 and $36 \%$ of the increase, respectively.

The cost of osteoporosis including value of QALYs lost was estimated to increase from approximately CHF 5.3 billion in 2010 to CHF 6.7 billion in 2025. The increase was estimated to be particularly marked in men (+39\%) compared to women (+20\%) (Table 18).

\section{Treatment uptake}

To estimate the uptake of individual osteoporosis treatments, sales data from IMS Health (2001-2011) were used to derive the number of defined daily doses (DDDs) sold per 100,000 persons aged 50 years or above (Fig. 2).

Adjusting the sales data for compliance allowed for an estimation of the proportion of the population aged 50 years or above who received any osteoporosis treatment (see Chapter 5 of the report "Osteoporosis in the European Union: Medical Management, Epidemiology and Economic Burden" for further
Fig. 2 Treatment uptake in Switzerland (defined daily doses [DDDs] per 100,000 persons aged 50 years or above)

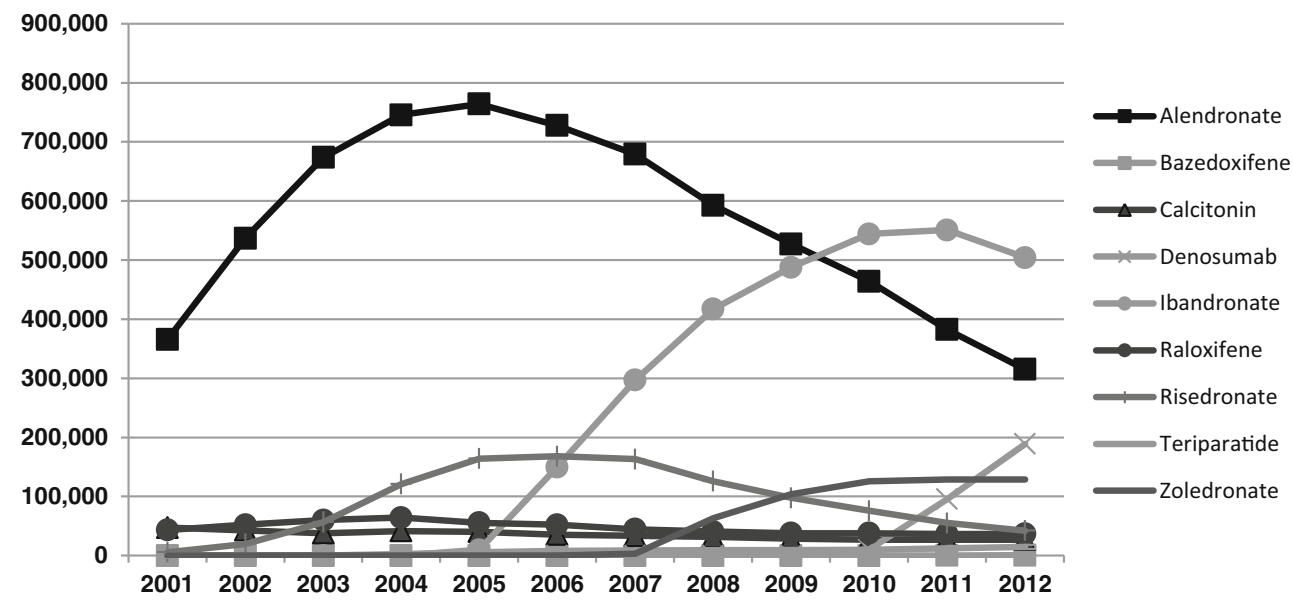

Table 19 Number of men and women eligible for treatment, treated and treatment gap in 2010

\begin{tabular}{lllll}
\hline & $\begin{array}{l}\text { Number potentially } \\
\text { treated }(1,000 \mathrm{~s})\end{array}$ & $\begin{array}{l}\text { Number eligible for } \\
\text { treatment }(1,000 \mathrm{~s})\end{array}$ & Difference $(1,000 \mathrm{~s})$ & Treatment gap (\%) \\
\hline Men & 18 & 28 & 10 & 36 \\
Women & 119 & 286 & 167 & 58 \\
\hline
\end{tabular}


details [1]). The proportion of persons over the age of 50 years who were treated increased from $1.7 \%$ in 2001 to $4.9 \%$ in 2011.

\section{Treatment gap}

In order to assess the potential treatment gap, the numbers of men and women eligible for treatment in Switzerland were defined as individuals with a 10-year fracture probability exceeding that of a woman with a prior fragility fracture derived from $\mathrm{FRAX}^{\circledR}$, equivalent to a fracture threshold (see Chapter 5 of the main report for further details [1]). Subsequently, these estimates were compared to the number of individuals who received osteoporosis treatment obtained from the analysis of IMS Health data. The treatment gaps in men and women were estimated at 36 and $58 \%$, respectively (Table 19). Note that the estimate of the treatment gap is conservative given that it assumes that current use of osteoporosis treatments is only directed to men and women at high risk.

Acknowledgments The methodology used for this report is the same as that used for the report "Osteoporosis in the European Union: Medical Management, Epidemiology and Economic Burden" [1]. The original report was sponsored by an unrestricted educational grant from the European Federation of Pharmaceutical Industry Associations (EFPIA) and the International Osteoporosis Foundation (IOF). We acknowledge the help of Helena Johansson and Prof. Anders Odén for their calculations of fracture probability. We thank O Ström and F Borgström, prominent authors of an earlier report covering a similar topic in a sample of EU countries, for providing the template for the present report.

\section{Conflicts of interest None.}

\section{References}

1. Hernlund E, Svedbom A, Ivergard M, Compston J, Cooper C, Stenmark J, McCloskey EV, Jonsson B, Kanis JA (2013) Osteoporosis in the European Union: medical management, epidemiology and economic burden. A report prepared in collaboration with the International Osteoporosis Foundation (IOF) and the European Federation of Pharmaceutical Industry Associations (EFPIA). Arch Osteoporos 8:136

2. SVGO (2010) Osteoporose: Prävention-Diagnostik-Behandlung

3. Lippuner K, Johansson H, Kanis JA, Rizzoli R (2009) Remaining lifetime and absolute 10 -year probabilities of osteoporotic fracture in Swiss men and women. Osteoporos Int 20: $1131-1140$

4. Wasserfallen JB, Krieg MA, Greiner RA, Lamy O (2008) Cost effectiveness and cost utility of risedronate for osteoporosis treatment and fracture prevention in women: a Swiss perspective. J Med Econ 11:499-523

5. Lippuner K, Johansson H, Borgstrom F, Kanis JA, Rizzoli R (2012) Cost-effective intervention thresholds against osteoporotic fractures based on FRAX ${ }^{\circledR}$ in Switzerland. Osteoporos Int 23:2579-2589

6. Chevalley T, Guilley E, Herrmann FR, Hoffmeyer P, Rapin CH, Rizzoli R (2007) Incidence of hip fracture over a 10-year period (1991-2000): reversal of a secular trend. BONE 40:1284-1289

7. Lippuner K, Popp AW, Schwab P, Gitlin M, Schaufler T, Senn C, Perrelet R (2011) Fracture hospitalizations between years 2000 and 2007 in Switzerland: a trend analysis. Osteoporos Int 22:2487-2497

8. Wilmoth J (2010) Human Mortality Database. University of California, Berkeley (USA), and Max Planck Institute for Demographic Research (Germany) Available at www mortality org (data downloaded on 2005-10-27)

9. Looker AC, Orwoll ES, Johnston CC Jr, Lindsay RL, Wahner HW, Dunn WL, Calvo MS, Harris TB, Heyse SP (1997) Prevalence of low femoral bone density in older U.S. adults from NHANES III. J Bone Miner Res 12:1761-1768

10. (2014) Documed. Arzneimittel-Kompendium der Schweiz

11. (201) United Nations Department of Economic and Social AffairsPopulation Division. World population prospects 